\title{
Social Anti-corruption -- A New Idea of Anti-corruption Governance in China
}

\author{
Yuhao Feng \\ Sun Yat-sen University, China \\ bobbyfengmr@gmail.com
}

\begin{abstract}
Since the reform and opening up, with the drastic economic and social transition, the problem of corruption in China has deteriorated in both width and depth. After brief examination of current major approaches of anti-corruption governance, we put forward a new idea of "social anticorruption" of the basis on new institutionalism, pointing out that the role of social forces in anticorruption should be highly valued. In order to develop a social anti-corruption system and cultivating a culture of integrity, we should improve social participation, strengthen social supervision, promote anti-corruption education, and improve legal development, ultimately making officials unwilling to corrupt.
\end{abstract}

Keywords: Anti-corruption governance, New institutionalism, Social anti-corruption.

\section{Introduction}

Anti-corruption governance is a worldwide problem. Since the reform and opening up, along with the rapid growth of China's economy, the corruption problem in China has become increasingly serious, which not only undermines the normal market competition order, but also erodes and even dissolves the legitimate foundation of the ruling party. "As the ruling party, the biggest danger we face is corruption," Xi jinping said in a speech on the party's 95th anniversary. In recent years, China's anti-corruption work has achieved fruitful and phased objectives through a number of measures, such as strengthening anti-corruption legislation, setting up the supervisory commission, and realizing the routine inspection by discipline inspection commission. "Since 2015, the national discipline inspection and supervision organ have practiced 'four forms' and used strict discipline to manage and govern the whole party, handling a total of 2.048 million people," according to the central discipline inspection commission report at the 19th CPC National Congress.

Although the achievement of the current anti-corruption is stimulating, in the context of the new historical era faced by the current anti-corruption work, how to fundamentally curb corruption is a problem that requires our careful consideration. Through the comparison of various countries, Fang Ning pointed out that there is no necessary relation between the completeness of anti-corruption system and the degree of corruption. "The anti-corruption system in developed countries is not complete, but on the whole, is relatively free from corruption[1]." Some scholars further pointed out that since the reform and opening up, a sound anti-corruption system has not stopped the spread of corruption, but increased the intensity of corruption transaction, which is a strong proof of the insufficiency of institutional anti-corruption to solve corruption problems[2]. Since the founding of the People's Republic of China, anti-corruption campaigns such as the "Three-anti Campaign" and the "Five-anti Campaign," which are carried out in the form of campaign-style governance, have not actually eradicated corruption.

In retrospect, it is precisely because of the lack of participation of social forces that institutional anti-corruption and campaign-style anti-corruption cannot fundamentally curb corruption. Therefore, we puts forward the concept of "social anti-corruption", and points out that the eradication of corruption should not only rely on the government-led system development or campaign-style governance, but should expand the channels for multiple social forces and mobilize them to participate, in order to actively build an incorruptible society. 


\section{Literature Review}

At present, the academic research on anti-corruption governance has multiple perspectives, both of which are important but limited. The research results mainly focus on the following three aspects: some scholars re-examined the important role of cultural factors in the study of corruption and anticorruption governance, and took it as an important factor to explain the emergence of corruption. Through the transnational comparison of cultural systems, some scholars used the tolerance of different cultural systems to corruption to explain the habitual corruption in some developing countries, believing it directly affects the occurrence of corruption[3]. Through the interpretation of the local concept of "personal obligation", some scholars believed that the abuse of "personal obligation" in daily relationship leads to the normal of "obligatory giving - obligatory accepting -obligatory return", thus inducing corruption[4]. Some scholars also paid attention to the significant role of cultural factors in preventing and punishing corruption. They put forward that "the development of clean government culture is the cultural foundation of institutional anti-corruption and process anti-corruption"[5], and that the basic path for incorruptible culture is to get involved in the process of anti-corruption governance by means of "inheriting the essence of Chinese incorruptible culture and carrying out the six progressive activities of incorruptible culture"[6]. In addition, some scholars emphasized that the occurrence of corruption mainly results from the imperfection of the system. Therefore, anti-corruption should be strengthened starting from the system. Some scholars noticed the phenomenon of system "fragmentation" and decentralization, lack of detailed content and lack of rules, attempting to perfect the current anti-corruption governance system[7]. Some scholars also pointed out the phenomenon of "institutional surplus," indicating that some systems do not achieve the original purpose, but become a breeding ground for corruption[8]. Some scholars also conducted in-depth study on the operating mechanism of anti-corruption governance. Besides, some scholars believed that the campaign-style anti-corruption "fully respects the masses' position as the subject of anti-corruption" and "has great deterrent power to the corruptionists"[9], while others held a negative attitude, believing that such measures do not pay attention to system development and is not sustainable[10].

The above research helps us to understand the root and generation mechanism of corruption, and it is undoubtedly of great benefit to broaden the perspective of anti-corruption governance research. However, the anti-corruption measures introduced by these three perspectives have their own shortcomings. Cultural anti-corruption emphasizes the transformation from corruption culture to clean government culture, yet culture is not subject to change in the short term, which determines that cultural anti-corruption has little effect on solving the current corruption problems. Institutional anticorruption can only punish the corruption after the incident, but cannot prevent it in advance. Additionally, institutional anti-corruption can only make public officials "do not dare to be greedy", rather than "do not want to be greedy." As some scholars have noted, the campaign-style anticorruption is particularly dependent on the decisions of leaders, thus lacking sustainability and going against the demands of a society with rule of law[11].

In the view of the researchers of new institutionalism, in addition to formal laws, government structure, election system and other formal systems, "rule, custom, convention, organization, culture, ritual and other informal systems"[12] should also be included in the research field. The new institutionalism rediscovers the role of institution in shaping political results, which not only provides a broad background and rich material for institutional change in reality, but also provides a novel perspective for relevant study. The individual in a particular culture is inevitably affected by the informal system: "the individual in a particular system internalizes the institutional norms associated with his/her role in the socialization process"[13]. Based on the theoretical framework of new institutionalism, we believes that in addition to formal rules and regulations, the informal system of "custom, convention, organization, culture and ritual" always influences and shapes the behavior of public officials. This also reminds us to pay attention to the research and application of social force, which has been neglected for a long time in the study of anti-corruption governance. 


\section{Social Anti-corruption -- A New Level of Anti-corruption Governance}

In this study, we define social force as the force outside the formal system, that is, outside public authorities such as government departments. Its main body mainly includes enterprises, society organizations, citizens and so on. The intervention of social force into anti-corruption governance is both a theoretical analysis and a realistic requirement. The existing research and practice of anticorruption governance have repeatedly proved that the existing anti-corruption mechanism cannot eradicate corruption, and its defects can be roughly attributed to two points. One is that the powerful anti-corruption measures within the system cannot effectively eradicate the institutional environment and cultural environment of corruption. Institutional anti-corruption can only deter public officials from bribery at best, but it still needs the informal system to play a positive role to make them unwilling to accept bribery from the heart. On the other hand, the cost of anti-corruption led by national force is too high. First, punishing corruption through the system requires considerable costs to investigate accountability. The process of investigation, trial and punishment of corruption cases requires a large number of humans, material and financial participation. Second, the cost of institutional development of institutional anti-corruption cannot be ignored. In the process of drafting and implementing new laws and regulations, various opinions need to be coordinated, the draft needs to be revised for several times, and the time consumed is relatively long. All these factors make the anti-corruption dominated by national force suffer high costs. However, the participation of social force in the anti-corruption governance overcomes the disadvantages of insufficient motivation caused by the dominance of a single national force, takes advantages of participation of multiple social subjects, forms a coordinated linkage between internal and external anti-corruption forces, and realizes the transformation of anti-corruption from top-down promotion to bottom-up participation mode. Therefore, we should attach importance to the use of social forces outside the institution, broaden the channels for social forces to participate in the anti-corruption governance, and shape the incorruptible cultural atmosphere of the whole society. This not only increases the cost of corruption, but also reduces the cost of anti-corruption governance.

In conclusion, social anti-corruption is an anti-corruption path with the participation of enterprises, citizens, social organizations and other social subjects, through expanding channels of anti-corruption participation, strengthening social supervision, strengthening education anti-corruption and improving legal system development, to shape an incorruptible society. This definition contains two meanings. On one hand, the participation of social forces in the anti-corruption governance, as well as the broadening of the channels for multi-subjects to participate in the anti-corruption, can help change the situation that only a single power in the country participates in anti-corruption, thus realizing the transformation of anti-corruption mode from top-down to bottom-up participation mode. On the other hand, social anti-corruption requires building up the integrity of the society as a whole, cultivating a good culture of refusing corruption and upholding integrity, and realizing the transformation of public officials' mindset from not daring to corrupt and being unable to corrupt, to being unwilling to corrupt.

\section{Policy Recommendations to Promote Social Anti-corruption}

The participation of social forces in the anti-corruption governance is an active exploration of the development of incorruptible administration and the only way to fight against corruption and build integiry in the new era. Major ways to encourage social forces to participate in anti-corruption governance are specified below.

\subsection{Improve Social Participation}

The first is to recruit professionals. When handling cases, we should pay attention to the role of accountants, auditors, lawyers, financial analysts, data scientists and other professionals, and recruit professionals from all walks of life to participate in anti-corruption governance. At the same time, intellectual contributions of universities and research institutes to anti-corruption governance should be brought into full play, such as holding "Anti-corruption Nantong Forum", "Taihu Forum", "Lijiang 
Forum" and other anti-corruption governance forums, and encouraging universities to conduct research on anti-corruption governance. The second is to establish a comprehensive mechanism involving the third party to evaluate the development of incorruptible administration. For example, in 2011, Huai 'an city in Jiangsu province commissioned a third-party investigation institution to conduct a survey on the integrity and efficiency status of municipal government departments, and took the evaluation results as an important basis for the evaluation of the integrity of all units. This approach not only improves the openness and transparency of power operation, but also effectively improves public participation in anti-corruption governance. Thirdly, we will explore the possibility of establishing an overseas pursuit system involving the third party. We will recruit professionals with knowledge of local laws, regulations, cultural practices and other aspects to improve the success rate of pursuit and asset recovery.

\subsection{Strengthen Social Supervision}

The first is to improve the news spokesman and anti-corruption information disclosure system. We need to establish an active information disclosure system and change the phenomenon that a news spokesman has only a nominal post but without power. In the process of the disclosure and investigation of corruption cases, a feasible interactive mechanism and inquiry mechanism for press release should be established. Second is to actively introduce social forces to participate in the supervision of the government. For example, the discipline inspection commission in Guangzhou has engaged 650 people from all walks of life as "Observers of a Incorruptible Guangzhou" to gather and report evidence of corruption in the name of a third party, and put forward suggestions for integrity development in Guangzhou. Third is to explore how to standardize citizen participation and build a public platform for network supervision. For example, with the rise of online platforms such as weibo, the concept of "network anti-corruption" has been attached importance to by the academic community. We should make effective use of existing online platforms, try to carry out specific public platforms for anti-corruption governance, and broaden the channels for citizens to participate in the network anti-corruption.

\subsection{Promote Anti-corruption Education}

First, we should pay attention to the publicity of anti-corruption, strengthen the guidance of public opinion on combating corruption and upholding integrity, and put emphasis on publicizing and investigating the "minor" corruption that the public may be exposed to daily, so as to reduce public tolerance to corruption. The second is to develop systematic and three-dimensional education. The formation of social values of integrity is a systematic project. Therefore, anti-corruption education should cover all the people at different ages. Through various forms such as anti-corruption propaganda films, posters, lectures, etc., the public should be aware that corruption based on traditional culture such as personal obligations and relationship is a cultural bad habit, so that people can consciously resist corruption and society can uphold the value of integrity. Third is to strengthen the rule of law education, to realize law-based administration, and to make residents know the law and abide by the law. We should build a clean and incorruptible society by improving and enhancing the law consciousness and legalization level in the whole society. Fourth, we should pay more attention to the punishment of public bribery, and gradually form among the public the value of dispising corruption and advocating integrity.

\subsection{Improve Legal Development}

The first is to explore concrete and long-term measures for the protection of the informers in accordance with the "Criminal Procedure Law." We should strengthen the participation of social forces in the anti-corruption governance. Protective measures for social forces are essential. We can learn from the US "Witness Protection Project" and take measures such as protecting the personal property of the informers and providing new identity for the informers, so as to effectively protect their rights and interests. Second is to improve the applicability and operability of existing laws and regulations, in order to enhance the development of relevant legal systems of network supervision. 
Social anti-corruption puts forward higher requirements on network supervision. Efforts should be made to improve the existing network rules and regulations, fill in blank areas, and standardize gray areas. Only when the rules are clear and the rights and responsibilities are clarified can the role of network supervision be effectively utilized in anti-corruption governance.

\section{Acknowledgements}

Thank for the support of National Social Science Foundation of China (Item NO. 17BSH084).

\section{References}

[1]. "Comparative Study on Political Development" Research Group of Chinese Academy of Social Sciences. Property Declaration and Notification System for Public Officials in Other Countries [M]. Beijing: China Social Sciences Press, 2013.

[2]. Liu Qijun. Empirical Analysis of China's Corruption Since the Reform and Opening-Up [J]. Political science research, 2013 (6): 39-51.

[3]. Remer, J. Scott. "Bribery and Its Ethical Implications for Aid Workers in the Developing World." Science and Engineering Ethics 23.1 (2017): 227-241.

[4]. Ke Zhujun, Yue Lei: A Cultural Examination of Chinese Corruption from the Angle of Personal Obligation [J]. Open Era, 2014(02): 210-223+10.

[5]. Liu Zhanhu: Institutional Anti-Corruption, Process Anti-Corruption and Cultural Upholding Integrity -- Exploration and Thinking on the Road of Combating Corruption and Upholding Integrity with Chinese Characteristics [J]. Marxism and Reality, 2014(01): 192-198.

[6]. Tan Laixing, Yin Shiyou: An Analysis on the Value Orientation and Basic Path of Incorruptible Culture in Anti-Corruption Development [J]. Exploration, 2014(03): 45-49.

[7]. Quai Zhengming: Exploration on the Path to Promote Institutional Anti-Corruption Development [J]. Study on Socialism with Chinese Characteristics, 2016, 1(6): 97-102.

[8]. Chen Jingyun, Yang Aiping: Institutional Surplus and Institutional Shortage: Structural Problems in the Development of a Clean Government System in China [J]. Academic Forum, 2011, 34(12): 54-59.

[9]. Hu Yang: The Internal Logic and Development Path of the Transformation of Anti-Corruption Mode with Chinese Characteristics [J]. Marxism and Reality, 2010 (4): 184-190.

[10]. Du Zhizhou: Changes and prospects of China's anti-corruption model [J]. Management Exploration, 2010 (2): 17-19.

[11]. March. James G. and Johan P. Olsen.1984. "The New Institutionalism: Organizational Factors in Political Life.” American Political Science Review 78(3):734-749.

[12]. Peter hall, Rosemary Taylor, Translated by He Junzhi. Political Science and the Three New Institutionalism [J]. Comparison of Economic and Social Systems, 2003(5):20-29. 